\title{
9. PUBLIC SERVICE DELIVERY OF LOCAL GOVERNMENT IN NEPAL IN 2015
}

- Suman Kharel ${ }^{9}$

\begin{abstract}
There has often been a gap between policy intentions and outcomes in the field of local governance and public service delivery. Analyzing the factors for these discrepancies requires multi-level approaches that relate policy decisions formulated at the national and international level with the decisions of local governance stakeholders. An Institutional Analysis and Development framework is necessary ability to link multiple local governance levels. Yet most common literatures have been limited to the study of collective action among local communities without considering higher institutional and government levels. To overcome this limitation, I set the methodology of the framework, which bridges the gap between institutional, historical analysis, power-centers, and discourse analysis. This article aims at examining current public service delivery status, analyzing challenges of public service delivery of local government and assessing people's experience of public service delivery of local government. In conclusion, current status of Local Government is illegal, incomplete and dysfunctional as it is in its service delivery. The major challenge is political instability and political reluctances for local election. The people's experience over the public service is below the satisfactory level.
\end{abstract}

Key Words: Public Service Delivery, Good Local Governance and Decentralization

\section{Background}

"A public service is a service benefiting the public that is provided for by the government because it is underprovided by the market. The public benefits from outputs and outcomes of the given service, not merely inputs. For instance, buildings, textbooks, teachers, assurance of pedagogical training and quality instruction, are all inputs for delivery of education service, but the public service is to yield an output of students with skills" (World Bank, 2014). So public service is a mechanism of government to provide its services to the people. Good governance is a process of executing a coherent governing plan for the nation based on the interests and priorities of the people. Its purports are to create a society based on the principles of inclusiveness, liberty, equality and cooperation. Those who are in the office, especially the elected ones, must represent the concerns, values and needs of the people and empower them through the realization of their basic rights, including the right to development and self-determination, by developing their access to markets, assets, goods and services and institutions (Dahal, Uprety, \& Subba, 2001).

\section{Principles and Policies of Local Self-governance:}

Government shall, in accordance with the guidelines set forth in the Constitution of Nepal, 1990, on decentralization; pursue the following principles and policies for the development of local selfgovernance system (Government of Nepal, 1999):

9 Mr. Kharel is PhD Scholar and teaches at Central Department of Rural Development, TU. 
Research Nepal Journal of Development Studies (Volume I Issue 1, 2018 May)

(a) Devolution of such powers, responsibilities, and means and resources are required to make the Local Bodies capable and efficient in local self-governance.

(b) Building and development of institutional mechanism and functional structure in Local Bodies capable the government to consider for local people and bearing responsibilities.

(c) Devolution of powers to collect and mobilize such means and resources as are required to discharge the functions, duties, responsibility and accountability conferred to the Local Bodies.

(d) Having the Local Bodies oriented towards establishing the civil society based on democratic process, transparent practice, public accountability, and people's participation, in carrying out the functions devolved on them.

(e) For the purpose of developing local leadership, arrangement of effective mechanism to make the Local Body accountable to the people in its own areas.

(f) Encouraging the private sector to participate in local self-governance in the task of providing basic services for sustainable development (Government of Nepal, 1999). However, practically the situation is quite opposite.

The concept of local governance encompasses institutional networks, interactions, collaborations and collective action in enhancing democratic practices at the local level are inevitable. This broader notion of local governance can foster democratic norms, values and practices of diverse types of locally functioning institutions. This is a new phenomenon evolving around the human collectivism. It is expected to provide spaces for diverse community groups and networks to promote and engage in collective action for locally defined agenda (Rai \& Paudel, 2011). The fundamental principle of local governance is to make the government responsive and accountable towards the people in its jurisdiction. The effectiveness of public service delivery depends largely on the capability, resources, inputs, and the motivation of frontline service providers at the local level. In Nepal a combination of de-concentrated line agencies and local bodies at the district, municipal, and village level provides inputs which are translated into delivery of service outputs and outcomes. Yet the relationships between line agencies and local bodies in service delivery are not well understood (World Bank, 2014).

The country is emerging from 10 years of violent civil conflict, and has been setting up new mechanisms to realize a new vision of Nepal. This has taken the form of a rights-based constitution and multi-party governments that have been the basis for many of the social policy initiatives undertaken thus far (Koehler \& Chopra, 2016). In such a critical situation public service may delay. Ensuring accountability and transparency of local level finance are critical elements for ensuring people's participation in local development.

Nepal's approach to local government has historically emphasized local participation and empowerment rather than creating institutions for service delivery. Over 50 years of subnational governance reforms have yielded an administrative framework of local bodies (LBs) consisting of 
75 District Development Committees (DDCs), 58 Municipalities and 3,915 Village Development Committees (VDCs). As the LBs' names indicate, their primary role is 'development', understood as carrying out small capital works, rather than local governments ensuring a mix of inputs for effective delivery of public services (World Bank, 2014). Fulfilling the requirement of the new constitution of Nepal in 2015, all old municipalities and villages (which were more than 3900 in number) were restructured into 753 new Municipalities and Villages. The former 75 District Development Committees (DDC) were also replaced by 77 new District Coordination Committees (DCC) which have much less power than the DDCs. At present there are 6 Metropolitan Cities, 11 Sub-Metropolitan Cities, 276 Municipalities, and 460 Rural Municipalities.

Accountability is a relationship between an actor and a forum, in which the actor has an obligation to explain and to justify his or her conduct; the forum can pose questions and pass judgment; and the actor may face consequences (Rai \& Paudel, 2011). Accountability entails government at all levels to be held responsible, by both its people and its elected bodies. Accountability also calls for a strict separation of local budgets and entrepreneurial activities at local level. However, in order to hold government accountable, we also need transparency. Transparency refers to norms and practices for legally legitimate centers of powers to disclose information about their decisions, actions and states of affairs to the public (Koehler \& Chopra, 2016). A transparent public financial accounting policy makes it possible to determine what the government has done and to compare planned with actual financial operations. Transparency denotes free access to governmental political and economic activities and decisions (Koehler \& Chopra, 2016).

The three-pillar 28 concept for the success of decentralization program may be relevant for understanding local governance discourse in Nepal. Based on this theoretical stance, the prevailing local governance discourse is not sufficient to address even one of the three. The creation and strengthening of local institutions can be ascertained with the links of five key governance issues:

1) The natural way of governing citizens;

2) Way of deepening democracy-power devolution reaching from central to the very local;

3) Accountability and responsiveness of the government;

4) Correction of the failure of top-down approach; and

5) The cost effectiveness of the government (Rai \& Paudel, 2011)

In the democratic society, decentralization is considered as a tool to develop partner institution in-between the local communities and the central institution known as local government which is closer to the people than central government. The World Bank distinguishes the conceptual and empirical distinction of decentralization in three dimensions: fiscal, administrative and political. Conceptually, fiscal decentralization refers to the process of granting autonomy to the local selfgovernment to mobilize financial resources (Shrestha, 2009). The impersonality of local bodies in goods and service delivery can only be achieved when its autonomy is no longer compromised 
by either central control or captured by local elites. In practice there are three limitations to autonomy. First, the principles of autonomy involve three basic rights-- distinct identity, ability to enter into contract and acquire, use and dispose its property. New institutional economic theorists argue that a precondition for development is a minimum legal and contractual structure and a set of well-defined and enforced property rights. Seen in this light, one can argue that the local government institutions have certain powers to make bylaws, raise revenue, carry out spending, recruit staff and adjudicate local disputes on a limited scale. But their autonomy is weakened by the fragmentation of local authorities on partisan lines causing a systematic erosion of the institutional dependence and centralized nature of services in a number of areas (Dahal, Uprety, \& Subba, 2001).

Nepal has experienced many political changes with different development approaches in different timeline. Many of them have been wasted due to the wrong strategy and approaches. The government after the restoration of democracy has been tried to implementation of decentralization model and even enacted the Local Self Governance Act (LSGA) 1999. There was huge discussion about the decentralization and the role of local government. But, again, the result to the citizen was ritual and as it was in past (Sharma, 2004). Local government bodies are independently elected by the local citizens. Politically they look like autonomous and independent. But, there is lacking of fiscal decentralization, no more required administrative decision power and even existence of many more contradictory acts with central government (Shresth, 2008). Due to as such many reasons local government compelled to depend with national government. So that local government institution is not found to be a responsive and accountable to provide the effective service to their citizens. There are some of the basic objectives of the decentralization and local government such as; make easy access on services to the people with quantity and quality, better utilization of the resources with the participation of people, avoid administrative service delay and difficulties, transparency in service delivery system and develop the participatory democratic system (Adhikary, 2010).

\section{Methodology}

This paper for discussion is largely based on review of available literature and conversations with local governance constituencies. The information was collected from secondary sources. Secondary sources include books, e-articles, articles, journals, reports, organizational publications, memorandum, and discussion papers etc. This paper also draws from review of media content. This study is completely based on secondary sources according as the references specified in the last section of this report.

\section{Discussion/Analysis}

\section{a. Public Service Delivery}

The practice of power for the management of economic and social resources in the development of the state the rules that answer the questions who, what and how decisions are made and enforced 
is Local governance whereas exercise of political authority and the use of institutional resources to manage society's problems and affairs and system that manages the public affairs related to social and economic resources locally is local governance (Regmi, Naidoo, Greer, \& Plkington, 2010) It has been argued that decentralization improves governance and public service delivery in four ways: (1) by increasing allocated efficiency adhering to the local needs and interests; (2) Improving efficiency through increased accountability of local governments; (3) Having fewer bureaucratic layers; and (4) By providing equitable opportunities for people (Regmi, Naidoo, Greer, \& Plkington, 2010). Similarly, these public services reforms in the form of a decentralization plan were implemented in Nepal on both political - strengthening democracy, accountability and participation by bringing government closer to its public - and economic grounds, such as the need to enhance the effectiveness, efficiency and responsiveness of public service provision (Regmi, Naidoo, Greer, \& Plkington, 2010)

Decentralization is defined as a socio-political process that transfers authority and responsibility in planning, management and decision-making from central government $(\mathrm{CG})$ to local authorities (LA). This is motivated in part by the desire to bring politicians and policy-makers closer to clients and to make systems more equitable, inclusive and fair as well as developing services to be more efficient and effective (Regmi, Naidoo, Greer, \& Plkington, 2010). However, decentralization in public service management continues to invite controversy and debate. Opponents of decentralization consider it the road to wrack and ruin, whereas its advocates see it as a panacea for reforming the public services in developing countries (Regmi, Naidoo, Greer, \& Plkington, 2010). Although the large body of literature has addressed the issue of decentralization and public sector development, the effects of decentralization on health services management and service delivery have been poorly assessed. One of the major reasons why people belonging to particular ethnic, linguistic, geographic, cultural communities felt discriminated by the regime is the poor state of public service delivery. Local governance is different from governmental authority. It is composed of local community, formal and informal institutions (BK, 2013).

Nepal still faces challenges in public service delivery. A sizeable number of people do not yet have access to basic public services. It is not uncommon to find people who have hardly had access to basic public services. Likewise, the efficiency and quality of the services being delivered is still generally low. Some health facilities, for example, are devoid of essential medicines and equipment or the medical personnel to work at the facilities. This poor state of service delivery has been causes of public concern both Central Government (CG) and Local Bodies (LBs) are responsible for providing services (Regmi, Naidoo, Greer, \& Plkington, 2010). The role of the CG in service delivery is critical, since it has the lead role in policy formulation, financing, regulation and actual delivery. However, the delivery of the CG has not been as efficient and effective, as would be desired, owing in part to a long chain involved from policy formulation to service delivery, lack of local control, poor match between financial allocation and local preferences among others. In recent years, the role of the LBs in service has been increasing. Delivery has substantially increased. However, they are yet to be established as institutions of public service delivery (Regmi, Naidoo, Greer, \& Plkington, 2010). 
Another source of inefficiency of the public service delivery system at the LB level is the lack of local control over their staff and thus, weak accountability relationships with clients/ citizens. Since the secretaries/chiefs of the LBs are centrally controlled in terms of their transfer, promotion, dismissal, salary and other pecuniary benefits, there is no incentive for these officials to be accountable to the LBs' political representatives. The constitution should provide for proper and adequate institutions ensuring accountability of the local governments without which there is no guarantee that local public service delivery will improve. In this regard, the role of the electoral system, intergovernmental relations and citizen empowerment in development programs is critically important. Likewise, fiduciary issues (financial management, procurement, budgeting, accounting, auditing and reporting) will require focus and clarity across the tiers of government. Rights to information, including enhanced social accountability mechanisms and cognizance of environmental and social safeguard issues will be important.

\section{b. Status of public Service Delivery on Local Government}

Institutionalize the process of development by enhancing the participation of all the people including the ethnic communities, indigenous people and down-trodden as well as socially and economically backward groups in bringing out social equality in mobilizing and allocating means for the development of their own region and in the balanced and equal distribution of the fruits of development (Government of Nepal, 1999). Theoretically it has been written but practically since last 20 years' local bodies are vacant.

Administratively, Nepal is divided into five development regions, 14 zones, 75 districts. A Village Development Committee (VDC) in Nepal is the lower administrative part of its Ministry of Federal Affairs and Local Development. Each district has several VDCs, similar to municipalities but with greater public-government interaction and administration. There are currently 3,157 village development committees in Nepal. Each VDC is further divided into several wards depending on the population of the district. Municipalities in Nepal are cities and towns meeting minimum criteria set out by the government. These criteria include a certain population, infrastructure and revenues. Presently, there are 217 municipalities in Nepal of which only 58 existed until 2014. 72 were established in May 2014, 61 in December 2014 and another 26 in September 2015. In addition, the Government of Nepal raised the administrative level of 7 existing municipalities to sub-metropolitan municipality for a total of 11 (Nepal, 2072). However, the local bodies restructuring committee has purposed 719 local bodies all over the country.

Most of the ministries have their offices at district level that are important to delivering services under their jurisdictions. And, some of the district level offices have their delivery units down to the VDC level. These service units are administratively and financially controlled and managed by district level offices that are in turn controlled by their regional offices, departments and ministries. As for the local governments, they exist at district level and below. DDCs function at district level and so do municipalities and VDCs in urban and rural areas. Ilakas are constituted of a number of VDCs, but they do not have independent status. The central government plays a significant 
role in providing public services (Nepal, 2072). It provides these services through ministries, departments, regional, and district and VDC level offices. Several public enterprises and other autonomous agencies are also involved in the service delivery process. However, for a number of reasons these service delivery models have not been able to rise up to the challenges. First, a long chain is involved between the service delivery units at local levels and the ministries in terms of budgeting, planning, programming and staffing. Budgets and programs are to be approved at the central level and passed on to the lower level, a process which takes significant amount of time. Despite improvements in recent years, annual budgets and work plans does not reach the operational level on time. Second, because of the centralized nature, there is very little scope for matching budget allocation and programming with local needs. Thirdly, the local people and authorities have almost no control over the staff and budget of the CG offices. (BK, 2013) The quality of services being delivered by the central agencies is still low.

\section{c. Challenges of Public Service Delivery on Decentralization}

Since begin of 1990s across the world countries have been faced with the challenges of simultaneous globalization and decentralization. The requirements towards more decentralized forms of governing have their point of departure in the necessity for more efficient delivery of various public services. In order to accept these requirements many countries had started with decentralization of their governing structures (Petak, 2004). However, the present discussion of federalization may affect the situation but there is an existence of an extensive debate over the relationship of federalism and decentralization among development practitioners. Federalism is often accompanied by decentralization, but it is not a necessary condition for decentralization, nor is decentralization a sufficient condition for federalism (Ghimire, 2061).

Resource mobilization is a challenging task for the economic development of a country. It mainly depends upon the system of governance, rule of law, efficiency of authorities, and so on. In this context, discussions were held with local authorities and personnel to collect the information regarding the challenges in local resource mobilization (Shrestha, 2009) Local Bodies could be oriented to fulfill the role of a local government that is more clearly responsible for public service outcomes (World Bank, 2014). The instruments of decentralization - the legal and institutional framework, the structure of service delivery responsibilities, and the inter-governmental fiscal system - must be designed to support the political objectives (Petak, 2004).

Good governance is a crucial precondition for economic growth. Only those countries are said to be having good governance which have a highly qualified public and private service mechanism that can withstand undue political pressure and manage all types of conflicts. This institutional determination requires enough social capital necessary for rationalizing public action as well as to steer social transformation. "The crucial Challenge is to build societal capacity for managing diversity and preventing social capital from being transformed into an instrument of exclusion and violent conflict (Dahal, Uprety, \& Subba, 2001). The challenge is how to accommodate underlying political pressures so that the developmental potential of decentralization can be realized and the 
risks minimized. The central challenge for Nepalese policy makers is to confront social power posed by societal complexities and asymmetries and their attendant effects on the composition of political power and authority. The other challenge is correcting the extreme urban bias and priority given to the non-agriculture sector by central planners. Similarly, to halt the steady retreat of the state from society, especially banks, police posts, schools, development projects and cooperatives, this has left a power vacuum increasingly filled by extra-constitutional forces. A society will be "more likely to cohere if people are socialized to have diverse wants with respect to private goods and similar wants with respect to collective goods. (Dahal, Uprety, \& Subba, 2001).

If Constituent Assembly - Legislative Parliament, government agencies, political parties, the private sector, civil society, the media and individuals make collective efforts, the weak condition of local governance can certainly be improved. All sectors and individuals need to work for promoting good governance, transparently and accountably. If concerted efforts are not made to protect endangered transparency and accountability, it is unlikely that transparency and accountability will be established and developed in the near future. The government, government agencies, the private sectors and donor agencies are unlikely to take the initiative in this issue, because economically, politically and socially backward sections of the society, whose survival depends on environmental resources, goods and services are their constituency for name sake only.

\section{d. People's perception of Local Governance on Good Governance}

Empowerment is one of the components of influencing stakeholders of local governance (BK, 2013). People expect simple basic needs, employments and infra-structure development but government has not been able to guarantee the needs. Currently, new initiatives are expanding the role of local governments - these include Poverty Reduction Strategies, which highlight an important role for local governments in poverty alleviation, but do not define how this role should be implemented (Ghimire, 2061). Also, there is an increased interest in the responsibility of sub-national governments in local economic development. Yet, it remains somewhat unclear, in practice, how local governments can help support business development. Capacity building, both in terms of human resources and financial support, has often been quoted as the principle obstacle in further decentralization processes. There is an ongoing need for capacity building and technical assistance, as well as practical lesson sharing and while there has been progress in this area, more needs to be done (Kunwar, 2010). In addition, assistance needs to be provided simultaneously "upwards" to the central and municipal government levels addressing advocacy and policy design and "downward" to the field-level stakeholders and local government authorities. Finally, improved donor coordination is fundamental to avoid conflicting advice, duplication and waste. Donors are integral partners in the decentralization process and measures need to be taken by developing countries to improve the coordination of efforts to provide efficient and effective assistance (Shresth, 2008)

In satisfaction surveys, a direct causal relation is presupposed between the quality of a certain 
service delivery and user satisfaction. If service quality increases, satisfaction increases as well. In reality however, this is not always the case because of differences in producer and consumer views on quality exchanges in quality and perceptions of it, but also of expectations service characteristics (Bouckaert \& Van de Walle, 2003). However where trust in government used to refer to belief that government will not become autocratic or arrest people indifferently, it now refers to more down to earth matters such as reliability of service delivery or the expectation that policy will correspond to one's wishes (Bouckaert \& Van de Walle, 2003). The factors determining trust in government are not necessarily the same for every country or political culture, and may differ over time. In political systems where public services are functioning in an impeccable way, evaluations of the public services will probably not be used to determine one's level of trust in government. Even more important is the impact of events on its service delivery (Bouckaert \& Van de Walle, 2003).

Decentralization and local self-governance are the bases of grassroots democracy, giving strong foundation to democracy at nation. When local interests, priorities, needs and resource base are different, autonomous local bodies should be empowered to manage the local affairs democratically in popular participation of the local people. Nepal acknowledged the philosophy of local governance and undertook efforts to decentralize central power and authority, in different points of time. Nepal have considerable constitutional, legislative and institutional framework. Prospects are there to institutionalize popular local democracy and bringing in socio-economic and political development in the lives of people at large, by the side a number of challenges are standing parallel (Adhikary, 2010). Issue of autonomy; fostering participation, inclusive and representative democracy; viability of financial resources; maintaining accountability and transparency; harmonizing the relationship with central government, NGOs, development partners and civil societies etc. are among the key challenges of Local bodies in Nepal.

Above all, a daunting or discoursing challenge appears to the contemporary local bodies as they are going through the absence of popularly elected representatives but led by civil bureaucrats. Recognizing Local Self Governance in constitution and addressing to these issues through effective legislative instruments can strengthen democracy at grassroots (Adhikary, 2010). The prevalent hierarchy in Nepalese society among rich and poor, low caste and high caste, male and female is the greatest challenge for the smooth functioning of any development endeavors. Due to such hierarchy, there is the degree of social, political and economic exclusion resulting to poverty. Mostly, women and ethnic groups are left out of the mainstream of development as they lack voice, empowerment, representation and access to economic opportunities. Therefore, weak governance is the key determining factor to exacerbate the poverty.

\section{Conclusion}

With the specified given socio-cultural setting, level of political culture and maturity, situation of conflict, central government influence and bureaucratic culture as well as limitations within the Local Bodies, practice of local governance missed the philosophy and spirit of the most democratic 
decentralization, subsidiary principle and local-self-governance. In conclusion the current status of Local Government is illegal, incomplete and dysfunctional as it is in its service delivery. The major challenge is political instability and political reluctances for local election. The people's experience over the public service is below the satisfactory level. The major issues to be cured as soon as possible at execution level are: the dominance of the All Party Mechanism (APM) and the absence of elected representatives, low representation of women and Dalits in decision-making bodies, overburdened office bearers: VDC secretary and LDO meaningless devolution, conflicts in the formation of the user's committees and elite domination. The use of contractors, shortage of technical personnel, no supervision or monitoring, incomplete and poor quality projects, no repair and maintenance, increased grant amount without institutional capacity and dependency on central grant. From the policy level it is very urgent to conduct a Local Election.

\section{References}

Adhikary, R. (2010). Local governance institutions in Nepal: status and challenges. Dhaka: North South University.

BK, U. B. (2013). Rethinking Local Governance in Nepal: A Case of Dalit Participation. Lalitpur: Social Inclusion Research Fund (SIRF), SNV Nepal .

Bouckaert, G., \& Van de Walle, S. (2003). Comparing measures of citizen trust and user satisfaction as indicators of 'good governance': Difficulties in linking trust and satisfaction indicators. International Review of Administrative Sciences, 69(3), 329-344.

CBS. (2012). Nepal in Figures. Kathmandu: Central Beureo of statistics.

Dahal, D., Uprety, H., \& Subba, P. (2001). Good Governance and Decentralization in Nepal. Kathmandu: Centre for Governance and Development Studies.

Ghimire, H. (2061). Developmental Practices in Nepal. Pulchhowk, Lalitpur: Sajha Prakashan.

Government of Nepal. (1999). Local Governance Act 2055 (1999). Kathmandu: Ministry of Law and Justice, Law Books Management Board.

(2016). In G. Koehler, \& D. Chopra, Development and social welfare Policy in south Asia. Newyork: Routladge.

Kunwar, K. B. (2010). Rural development in Developing Countries (Policies, Strategies, and Practices). Kathmandu: Meena Publication.

Nepal, G. o. (2072). Brief introduction of Nepalese Local Bodies. Kathmandu: MOFALD.

Pandey, D. R. (1999). Nepal's Failed Development: Reflection on Mission and Maladies. 
Kathmandu: Nepal South Asia Centre.

Petak, Z. (2004). How to Measure Decentralization: The Case-Study from central European countries. University of Zagreb, Croatia (pp. 2-6). Bloomington: The third pentannual workshop on workshop.

Rai, J. K., \& Paudel, N. S. (2011). Discourses of Local Governance in Nepal:. Kathmandu: Forest Action.

Regmi, K., Naidoo, J., Greer,A., \& Plkington, P. (2010). Understanding the effect of decentralisation on health services the Nepalese experience . Journal of Health Organization and Management, 361-382.

Sharma, P. (2004). Local Development Planning in Nepal An emperical experience. Kathmandu: Kshitiz Publication.

Shresth, C. L. (2008). State of Tourism in Nepal- An Overview. In R. P. Upadhyaya, Readings in Rural Tourism (pp. 249-262). Kathmandu, Nepal: Sunlight Publication(students' Books).

Shrestha, B. (2009). Fiscal Decentralization and Local Resource Mobilization in Nepal. Nepalese Journal of Public Policy and Governance, xxv(2), 55-72.

World Bank. (2014). Local Service Delivery in Nepal. Kathmandu: World Bank. 